University of Nebraska - Lincoln

DigitalCommons@University of Nebraska - Lincoln

Public Health Resources

Public Health Resources

2002

\title{
Increased Hippocampal Volume in Schizophrenics' Parents with Ancestral History of Schizophrenia
}

Josette G. Harris

University of Colorado School of Medicine, Denver, CO

David A. Young

University of Colorado School of Medicine, Denver, CO

Donald C. Rojas

University of Colorado School of Medicine, Denver, CO

Ana Cajade-Law

University of Colorado School of Medicine, Denver, CO

Ann Scherzinger

University of Colorado School of Medicine, Denver, CO

See next page for additional authors

Follow this and additional works at: https://digitalcommons.unl.edu/publichealthresources

Part of the Public Health Commons

Harris, Josette G.; Young, David A.; Rojas, Donald C.; Cajade-Law, Ana; Scherzinger, Ann; Nawroz, Safia; Adler, Lawrence E.; Munro Cullum, C.; Simon, Jack; and Freedman, Robert, "Increased Hippocampal Volume in Schizophrenics' Parents with Ancestral History of Schizophrenia" (2002). Public Health Resources. 48.

https://digitalcommons.unl.edu/publichealthresources/48

This Article is brought to you for free and open access by the Public Health Resources at DigitalCommons@University of Nebraska - Lincoln. It has been accepted for inclusion in Public Health Resources by an authorized administrator of DigitalCommons@University of Nebraska - Lincoln. 
Authors

Josette G. Harris, David A. Young, Donald C. Rojas, Ana Cajade-Law, Ann Scherzinger, Safia Nawroz, Lawrence E. Adler, C. Munro Cullum, Jack Simon, and Robert Freedman 


\title{
Increased hippocampal volume in schizophrenics' parents with ancestral history of schizophrenia
}

\author{
Josette G. Harris, ${ }^{a, *}$, David A. Young ${ }^{\mathrm{b}}$, Donald C. Rojas ${ }^{\mathrm{a}}$, Ana Cajade-Law ${ }^{\mathrm{c}}$, \\ Ann Scherzinger ${ }^{c}$, Safia Nawroz ${ }^{\mathrm{f}}$, Lawrence E. Adler ${ }^{\mathrm{a}, \mathrm{d}}$, \\ C. Munro Cullum ${ }^{\mathrm{e}}$, Jack Simon ${ }^{\mathrm{c}}$, Robert Freedman ${ }^{\mathrm{a}, \mathrm{d}}$ \\ ${ }^{a}$ Department of Psychiatry, University of Colorado School of Medicine, 4200 E. $9^{\text {th }}$ Avenue, Denver, CO 80262, USA \\ ${ }^{\mathrm{b}}$ Department of Preventive Medicine and Biometrics, University of Colorado School of Medicine, 4200 E. $9^{\text {th }}$ Avenue, Denver, CO 80262, USA \\ ${ }^{c}$ Department of Radiology, University of Colorado School of Medicine, 4200 E. $9^{\text {th }}$ Avenue, Denver, CO 80262, USA \\ ${ }^{\mathrm{d}}$ Denver Veterans Affairs Medical Center, 1055 Clermont, Denver, CO 80220, USA \\ ${ }^{\mathrm{e}}$ Department of Psychiatry, University of Texas Southwestern Medical Center at Dallas, 5323 Harry Hines Boulevard, \\ Dallas, Texas, 75390, USA \\ ${ }^{\mathrm{f}}$ Aurora Community Mental Health Center, 14301 E. Hampden, Aurora, CO 80014, USA
}

Received 1 December 2000; revised 24 May 2001; accepted 29 May 2001

\begin{abstract}
Objective: Decreased hippocampal volume is one of the hypothesized pathological features of schizophrenia, but it is not known if this abnormality is familially transmitted. The aim of this study was to measure the hippocampal volume of the parents of schizophrenic probands, in relationship to the apparent transmission of genetic risk.

Method: Eighteen subjects from families consisting of a schizophrenic proband and two clinically unaffected parents were studied. Probands were compared to six control subjects, matched for age, sex, and educational level. The six families were selected so that only one parent had an ancestral family history of schizophrenia. The volumes of both hippocampi were measured by magnetic resonance imaging and adjusted for age and whole brain volume.

Results: The total hippocampal volumes of the parents with ancestral family history of schizophrenia were significantly larger than those of their schizophrenic offspring.

Conclusions: This study suggests that decreased hippocampal volume in schizophrenia is not a familially transmitted abnormality. Rather, it appears that clinically unaffected parents who transmit apparent genetic risk for schizophrenia may have increased hippocampal volume, which may be a protective factor against the illness.
\end{abstract}

The relationship of structural brain pathology to the pathogenesis of schizophrenia remains elusive. Several studies have shown evidence of decreased

\footnotetext{
* Corresponding author. Address: Department of Psychiatry, C268-71, University of Colorado School of Medicine, 4200 East Ninth Avenue, Denver, CO 80262, USA. Tel.: +1-303-315-4610; fax: +1-303-315-5347.
}

volume of specific brain structures, notably the hippocampus (Bogerts et al., 1985; Cannon et al., 1989; Jeste and Lohr, 1989; Suddath et al., 1989) but other brain areas have been implicated as well (Turetsky et al., 1995; McCarley et al., 1993; Andreasen et al., 1989). However, the differences reported between schizophrenic patients and unrelated normal controls have typically been small, perhaps reflecting 
the wide range of brain structure volumes in the normal population (Nelson et al., 1998). Several investigators have suggested that it might be helpful to compare schizophrenics to their clinically well relatives to control for familial effects on brain size (Cannon and Marco, 1994; Reveley et al., 1982; Suddath et al., 1990; Chau et al., 2000; Sharma et al., 1999; Staal et al., 2000). That approach has been particularly beneficial for the study of monozygotic twins discordant for schizophrenia. With genetic differences controlled, the affected members of the twin pair showed smaller hippocampal volumes and larger ventricular to brain ratios than their unaffected twins (Reveley et al., 1982; Suddath et al., 1990). This finding raises further questions, however, as it implies that diminished hippocampal volume is not part of the genetic diathesis of the illness. Indeed, increased ventricular to brain ratios have been found in schizophrenics without an apparent family history of the illness (DeQuardo et al., 1996), but increased ratios and fronto-parietal atrophy have also been identified in members of a pedigree segregating a genetic allele linked to schizophrenia in their family (Shihabuddin et al., 1996). The purpose of the present study was to further investigate the relationship of hippocampal volume to the apparent genetic transmission of risk for schizophrenia, by examining this measure in schizophrenic probands and their parents.

Despite ample evidence for genetic factors in schizophrenia, the illness does not show simple genetic transmission. Its pathogenesis likely involves multiple genetic and environmental elements, with possible inheritance of risk factors from both parents. Some of these risk factors may be specific to schizophrenia, while others may be less specific and contribute to the expression of the illness by causing more generalized brain dysfunction (Gottesman and Shields, 1972). It has been hypothesized that such nonspecific brain dysfunction may be the final critical factor in determining which individuals develop clinical illness in a pedigree that is also segregating specific genes related to schizophrenia. If a family appears to have unilineal inheritance of schizophrenia through an asymptomatic parent with an ancestral family history of schizophrenia, then it is possible that this parent has some of the specific neurobiological dysfunctions related to schizophrenia, with fewer of the non-specific characteristics than their offspring with schizophrenia.
We have used this strategy to study the possibility of inheritance of several psychophysiological and neuropsychological deficits related to schizophrenia (Waldo et al., 1994; Harris et al., 1996; Ross et al., 1998). Our approach has been to ascertain schizophrenic probands who have both their biological parents available for study. Using a systematic family interview process, the presence or absence of ancestral family history of schizophrenia is identified for each parent. In approximately $50 \%$ of families, one and only one parent has an ancestral history of schizophrenia. These clinically asymptomatic parents are putative obligate carriers for schizophrenia, because of the likelihood that they transmit genetic risk in these unilineal families. Abnormalities in P50 auditory sensory gating, diminished performance in attentional tasks, and elevated saccadic intrusion into smooth pursuit eye movements have been identified in these apparent obligate carrier parents of patients with schizophrenia (Waldo et al., 1994; Harris et al., 1996; Ross et al., 1998). The spouses, who did not have ancestral histories of schizophrenia, also did not manifest these deficits. Identification of heritable biological traits in schizophrenia by this strategy has led to the identification of at least one positive genetic linkage, based on the familial distribution of the P50 auditory sensory gating abnormality (Freedman et al., 1997). The present study uses this methodology to investigate whether differences in hippocampal volume show a similar distribution.

\section{Method}

\subsection{Subjects}

Twenty-four subjects were studied. They consisted of 6 schizophrenic probands, and their 12 biological parents. In addition, there were 6 control subjects, demographically matched to the probands. Families were included in the study if probands: (a) met criteria for schizophrenia as confirmed by the Structured Interview for DSM-III-R (SCID; Spitzer et al., 1990), and (b) had a unilineal family history for schizophrenia in the biological parents. Families were excluded if either parent had past or current symptoms 
of schizophrenia. After complete description of the study to the subjects, written informed consent was obtained.

\subsection{Family history}

Parents were individually interviewed to obtain family histories, using Family History Research Diagnostic Criteria (Endicott et al., 1978). Family pedigrees were constructed outward to fourth degree relatives. Each parent constructed a pedigree for him or herself and for the spouse for cross validation. When a potential schizophrenic relative was identified, a second key relative was contacted to verify the positive ancestral history provided by the parent. This resulted in the initial identification of eight families with a positive ancestral history for schizophrenia. In one family, a parent was diagnosed with schizophrenia in remission who also had a positive family history of schizophrenia. In a second family, the parents declined to participate. Consequently, these two families were excluded from the study, resulting in a final set of six families. The spouses of the six parents with positive ancestral histories of schizophrenia all had negative family histories of schizophrenia. There were no significant differences in the total number of family members studied in the positive versus negative pedigrees. Two parents had first degree relatives affected, two had second degree relatives, and two had third degree relatives.

Control subjects were matched to the probands for age, sex, and years of education. They were healthy volunteers recruited via newspaper advertisement and were screened using the SCID-NP to ensure absence of history of psychiatric and neurologic illness, and substance use. In addition, control subjects were interviewed to rule out family history of schizophrenia.

\subsection{Magnetic resonance imaging}

Magnetic resonance images of the head were obtained using a 1.5 Tesla, Signa General Electric Medical Systems scanner. Coronal three dimensional spoiled gradient echo sequence images of the entire head were obtained. The scanning parameters were TR $45 \mathrm{msec}$, TE $5 \mathrm{msec}$, flip angle of 45 , field of view $24 \mathrm{~cm}$, and matrix size of $256 \times 128$, reconstructed to $256 \times 256$. Slices were contiguous, and were either 1.5 or $1.7 \mathrm{~mm}$ thick. Volumetric measurement of the left and right hippocampus proceeded by outlining the structure in anterior to posterior sequential slices. The most reliable structure clearly separating the amygdala from the hippocampus is the temporal horn of the lateral ventricle. This was used as the starting point for the most anterior aspect of the hippocampus. The most posterior section measured was the section where the crus of the fornix clearly separated from the hippocampus and its fimbria. This protocol leaves a small segment of the tail of the posterior hippocampus outside the measured hippocampal volume. Volumes were corrected for total brain volume, although such volumetric adjustments were not found to increase the effect size for the difference between schizophrenics and controls in a recent meta-analytic review (Nelson et al., 1998).

Consensus on identification of relevant landmarks was achieved via training sessions with two neuroradiologists (ACL and JS), using cases from a larger pool of subjects not included in the current study. Two of the authors ( $\mathrm{JH}$ and $\mathrm{SN}$ ), blind to subject group status, outlined the right and left hippocampus on contiguous slices displayed on a Sun Workstation. Pixels were then summed across all contiguous slices and multiplied by slice thickness to obtain right, left, and total hippocampal volumes. Two cases from the final sample were randomly selected in which both $\mathrm{JH}$ and SN outlined bilateral hippocampus and calculated right, left, and total volumes. The interrater reliability for individual measurement in slices for these two cases, as measured by intraclass correlations, ranged from 0.83 to 0.99 . In addition, two cases were randomly selected and hippocampi outlined twice by the same individual with an interval of two weeks between the outlining sessions. The intrarater reliabilities for these measurements, including the total brain volume measurements, were 0.99 .

\subsection{Data analyses}

Hippocampal volumes were calculated adjusting for MRI slice thickness (1.5 or $1.7 \mathrm{~mm})$, and then analyzed using a linear modeling approach (Littell et al., 1996). The model employed accounts for the familial relatedness of the proband and his/ her two parents as well as the demographic 
Table 1

Comparison of hippocampal volumes

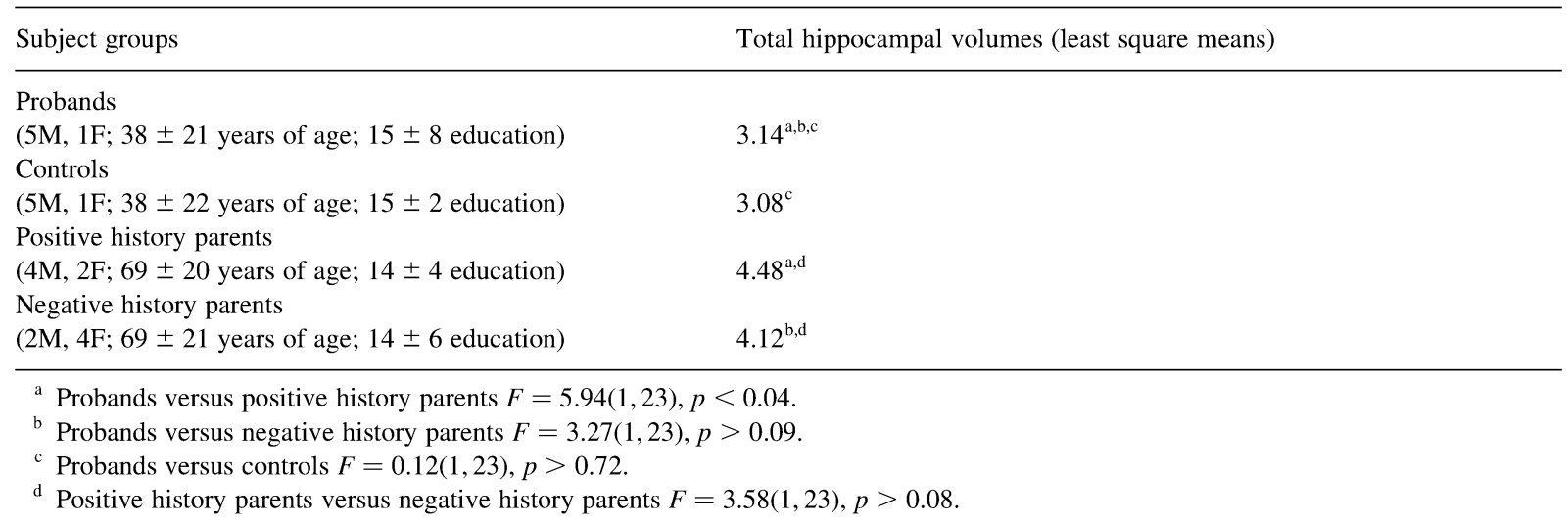

matching of each proband to a control. The effect of family was highly significant $\left(F_{5,23}=8.88\right.$, $p<.001)$. It was considered necessary a priori to adjust hippocampal volumes for subject age and whole brain volume, although interactions between group and the latter two variables did not turn out to be significant. Comparisons of interest were examined using $F$-tests: between probands and their positive history parents, between probands and their negative history parents, between probands and their age-matched controls, and between positive and negative history parents. Analyses were implemented with SAS statistical software (SAS STAT, Version 8, SAS Institute, Inc., Cary, North Carolina, 1999).

\section{Results}

\subsection{Hippocampal volumes}

Table 1 presents the least square means for the adjusted total hippocampal volumes for all groups and group comparison results. The overall model $F$ statistic was $F_{10,23}=5.14, p<0.005$. Hippocampal volumes of positive history parents were significantly greater than probands $\left(F_{1,23}=5.94, p<0.04\right)$. No other comparisons were significant. The difference in hippocampal volume between positive history parents and the probands was $1.33 \pm 0.55 \mathrm{~cm}^{3}$, or about a $28 \%$ decrease in volume between parents and their offspring. Analyses of left and right volumes separately revealed significant differences between family history positive parents and probands only on the right side $(p<.05)$.

\section{Discussion}

The significant finding in this study is the larger hippocampal volumes in the apparent obligate carrier parents with positive ancestral history of schizophrenia. Although no other study has directly addressed the issue of transmission of this structural feature through unaffected parents, nonetheless this finding is congruent with results from two other studies. In both studies, apparent clinically unaffected carriers of genetic risk for schizophrenia had significantly larger hippocampal volumes than schizophrenic probands. In a study of monozygotic twins discordant for schizophrenia, Suddath et al. (1990) found enlarged lateral and third ventricles and reduced hippocampal volumes in the schizophrenic twin, compared to the clinically unaffected twin. Similarly, in a comparison of schizophrenics with their clinically unaffected siblings, Waldo et al. (1994) found evidence that inheritance of one putative aspect of genetic risk, as indicated by a neuronal deficit in P50 auditory sensory gating, is distinguishable from the hippocampal abnormalities found in schizophrenia. Abnormal P50 sensory gating is found in both schizophrenic and some non-schizophrenic siblings in many families; this sensory gating deficit is inherited as a single gene phenotype (Freedman et al., 1997). However, 
clinically unaffected siblings with abnormal P50 sensory gating have larger hippocampal volumes than their schizophrenic siblings. Thus, the shared sensory gating deficit is distinct from an abnormality in hippocampal volume.

The absence of a significant decrement in hippocampal volume between the probands and controls in the present study is consistent with the small effect size $(0.3-0.4)$ found in the meta-analytic review of hippocampal volume differences between normals and schizophrenics (Nelson et al., 1998). Thus, a difference between schizophrenics and unrelated controls is not likely to be found consistently in small sample sets. However, differences between schizophrenics and their unaffected relatives have been detected in relatively small samples in several previous studies (Suddath et al., 1990; Waldo et al., 1994) and in the present study. The distinction between the two types of studies may be that the comparisons between schizophrenics and their relatives detect differences, because many other genetic and environmental influences on hippocampal size are controlled, whereas in a comparison in the general population these other factors can cause a great deal of variance that obscures the difference due to schizophrenia.

The smaller volumes of the probands compared to their negative history parents, while not significant, may be expected, given that schizophrenia is associated with decreased hippocampal volume (Nelson et al., 1998). What might not have been hypothesized is that the parent who is the presumed carrier of genetic risk for schizophrenia actually has the largest volume. The larger volume in the obligate carrier parent is perhaps a protective factor against psychosis. In the neuropsychological evaluation of these same parents, we found that they share the attentional dysfunction that also characterizes the probands, but not the deficits in learning (Harris et al., 1996). Some, but not all, studies have shown that reduced volumes of temporolimbic structures have a relationship to diminished performance on specific neuropsychological measures in schizophrenia (Golden et al., 1980; Hoff et al., 1992; Nestor et al., 1993). A population of schizophrenic individuals is likely the outcome of multiple selections for both genetic and environmental factors that result in brain dysfunction. Parents of schizophrenics would be expected to share some of these factors, but would also be expected to have positive aspects of brain function that facilitate psychosocial success and the successful acquisition of a parental role. Perhaps this selection of environmental and genetic factors results in increased hippocampal development, which in turn allows psychosocial success, despite a genetic predisposition to psychosis. Various etiologies of structural abnormalities in schizophrenia have been proposed, including perinatal injury and seasonal environmental factors, such as intrauterine viral exposure. Higher rates of nonspecific birth complications have been identified in affected siblings and monozygotic twins compared with their unaffected siblings and co-twins. These complications have typically been unrelated to measures of various cortical and cerebellar structures (Cannon et al., 1989; DeLisi et al., 1998), although one study that compared patients with histories of severe pregnancy and birth complications to patients without such histories from multiply affected families, found a reduction in left hippocampal volume (Stefanis et al., 1999). Ventricle brain ratio also does not appear to be related to seasonal environmental factors (DeQuardo et al., 1996), further emphasizing the difficulty in explaining the etiology of structural defects in schizophrenia when they are identified. Hippocampal volume changes may also be caused by other factors, such as stress-related glutamate excitotoxicity (c.f. Sapolsky, 1996).

Although only the comparison of positive history parents and probands was significant, the negative history parents also tended to have larger hippocampal volumes compared with both the probands and the proband controls. While the families in this study were selected for their unilineal histories of schizophrenia, a bilineal pattern of inheritance in the probands cannot be definitively ruled out using the family history interview method. If some of the identified negative history parents indeed had genetic susceptibility, they too might express the larger hippocampal volumes. In a recent investigation of schizophrenia in families preselected for their unilineal inheritance, the genetic evidence in fact supported a recessive gene model of bilineal inheritance (Brzustowicz et al., 2000).

In conclusion, the available evidence suggests that cerebral anatomical abnormalities may represent a 
secondary, likely non-inherited, factor which combined with genetic risk for schizophrenia, increases the chances that an individual will manifest the illness. The present findings are limited by the small number of families studied, the restriction of ascertainment to unilineal families with clinically unaffected parents, and the restriction of measurement to a single structure. Other structures whose volume is also diminished in schizophrenia may show similar or different familial distributions of abnormalities (Andreasen et al., 1998; Buchanan et al., 1998; Portas et al., 1998)

\section{References}

Andreasen, N.C., Ehrhardt, J.C., Swayze, V.W., Alliger, R.J., Yuh, W.T.C., Cohen, G.M., Ziebell, S., 1989. Magnetic resonance imaging of the brain in schizophrenia: the pathophysiologic significance of structural abnormalities. Arch. Gen. Psychiatry $47,35-44$.

Andreasen, N.C., Paradiso, S., O'Leary, D.S., 1998. Cognitive dysmetria as an integrative theory of schizophrenia: A dysfunction in cortical-subcortical-cerebellar circuitry? Schizophr. Bull. 24, 203-218.

Bogerts, B., Meertz, E., Bausch-Schonfeldt, R., 1985. Basal ganglia and limbic system pathology in schizophrenia: a morphometric study of brain volume and shrinkage. Arch. Gen. Psychiatry 42, 784-791.

Brzustowicz, L.M., Hodgkinson, K.A., Chow, E.W.C., Honer, W.G., Bassett, A.S., 2000. Location of a major susceptibility locus for familial schizophrenia on chromosome 1q21-22. Science 288, 678-682.

Buchanan, R.W., Vladar, K., Barta, P.E., Pearlson, G.D., 1998. Structural evaluation of the prefrontal cortex in schizophrenia. Am. J. Psychiat. 155, 1049-1055.

Cannon, T.D., Marco, E., 1994. Structural brain abnormalities as indicators of vulnerability to schizophrenia. Schizophr. Bull. 20, 89-102.

Cannon, T.D., Mednick, S.A., Parnas, J., 1989. Genetic and perinatal determinants of structural brain deficits in schizophrenia. Arch. Gen. Psychiatry 46, 883-889.

Chau, S.E., Sharma, T., Takei, N., Murray, R.M., Woodruff, P.W., 2000. A magnetic resonance imaging study of corpus callosum size in familial schizophrenic subjects, their relatives, and normal controls. Schizophr. Res. 41, 397-403.

DeLisi, L.E., Dauphinais, I.D., Gershon, E.S., 1998. Perinatal complications and reduced size of brain limbic structures in familial schizophrenia. Schizophr. Bull. 14, 185-191.

DeQuardo, J.R., Goldman, M., Tandon, R., 1996. VBR in schizophrenia: relationship to family history of psychosis and season of birth. Schizophr. Res. 20, 275-285.

Endicott, J., Andreason, N., Spitzer, R.L., 1978. Family HistoryResearch Diagnostic Criteria. 3rd ed. National Institute of Mental Health, Washington, DC.
Freedman, R., Coon, H., Myles-Worsley, M., Orr-Urtreger, A., Olincy, A., Davis, A., Polymeropoulos, M., Holik, J., Hopkins, J., Hoff, M., Rosenthal, J., Waldo, M.C., Reimherr, F., Wender, P., Yaw, J., Young, D.A., Breese, C.R., Adams, C., Patterson, D., Adler, L.E., Kruglyak, L., Leonard, S., Byerley, W., 1997. Linkage of a neurophysiological deficit in schizophrenia to a chromosome 15 locus. Proceedings of the National Academy of Sciences of the United States of America 94, 587-592.

Golden, C.J., Moses, J.A., Zelazowski, R., Graber, B., Zatz, L.M., Horvath, T.B., Berger, P.A., 1980. Cerebral ventricular size and neuropsychological impairment in young chronic schizophrenics. Measurement by the standardized Luria-Nebraska Neuropsychological Battery. Arch. Gen. Psychiatry 37(6) 619-623.

Gottesman, I., Shields, J., 1972. Schizophrenia and Genetics. Academic Press, New York.

Harris, J.G., Adler, L.E., Young, D.A., Cullum, C.M., Rilling, L.M., Cicerello, A., Intemann, P.M., Freedman, R., 1996. Neuropsychological dysfunction in parents of schizophrenics. Schizophr. Res. 20, 253-260.

Hoff, A.L., Riordan, H., O’Donnell, D.W., Stritzke, P., Neale, C., Boccio, A., Anand, A.K., DeLisi, L.E., 1992. Anomalous lateral sulcus asymmetry and cognitive function in first-episode schizophrenia. Schizophr. Bull. 18, 257-272.

Jeste, D.V., Lohr, J.B., 1989. Hippocampal pathologic findings in schizophrenia: A morphometric study. Arch. Gen. Psychiatry 46, 1019-1024.

Littell, R.C., Milliken, G.A., Stroup, W.W., Wolfinger, R.D., 1996. SAS System for Mixed Models. SAS Institute, Cary, North Carolina.

McCarley, R.W., Shenton, M.E., O'Donnell, B.F., Faux, S.F., Kikinis, R., Nestor, P.G., Jolesz, F.A., 1993. Auditory P300 abnormalities and left posterior superior temporal gyrus volume reduction in schizophrenia. Arch. Gen. Psychiatry 50, 190-197.

Nelson, M.D., Saykin, A.J., Flashman, L.A., Riordan, H.J., 1998. Hippocampal volume reduction in schizophrenia as assessed by magnetic resonance imaging. Arch. Gen. Psychiatry 55, 433440.

Nestor, P.G., Shenton, M.E., McCarley, R.W., Haimson, J., Smith, R.S., O’Donnell, B., Kimble, M., Kikinis, R., Jolesz, F.A., 1993. Neuropsychological correlates of MRI temporal lobe abnormalities in schizophrenia. Am. J. Psychiat. 150(12) 1849-1855.

Portas, C.M., Goldstein, J.M., Shenton, M.E., Hokama, H.H., Wible, C.G., Fischer, I., Kikinis, R., Donnino, R., Jolesz, F.A., McCarley, R.W., 1998. Volumetric evaluation of the thalamus in schizophrenic male patients using magnetic resonance imaging. Biol. Psychiat. 43, 49-59.

Reveley, A.M., Reveley, M.A., Clifford, C.A., Murray, R.M., 1982. Cerebral ventricular size in twins discordant for schizophrenia. Lancet 1, 540-541.

Ross, R.G., Harris, J.G., Olincy, A., Radant, A., Adler, L.E., Freedman, R., 1998. Familial transmission of two independent saccadic abnormalities in schizophrenia. Schizophr. Res. 30, 59-70.

Sapolsky, R.M., 1996. Why stress is bad for your brain. Science 273, 749-750. 
Sharma, T., Lancaster, E., Sigmundsson, T., Lewis, S., Takei, N., Gurling, H., Barta, P., Pearlson, G., Murray, R., 1999. Lack of normal pattern of cerebral asymmetry in familial schizophrenic patients and their relatives - The Maudsley Family Study. Schizophr. Res. 40, 11-120.

Shihabuddin, L., Silverman, J.M., Buchsbaum, M.S., Seiver, L.J., Luu, C., Germans, M.K., Metzger, M., Mohs, R.C., Smith, C.J., Spiegel-Cohen, J., Davis, K.L., 1996. Ventricular enlargement associated with linkage marker for schizophrenia-related disorders in one pedigree. Molecular Psychiatry 1, 215-222.

Spitzer, R.L., Williams, J.B.W., Gibbon, M., First, M.B., 1990. Structured Clinical Interview for DSM-III-R — Patient Edition (SCID-P, Version 1.0). American Psychiatric Press, Washington, DC.

Staal, W.G., Hulshoff Pol, H.E., Schnack, H.G., Hoogendoorn, M.L., Jellerma, K., Kahn, R.S., 2000. Structural brain abnormalities in patients with schizophrenia and their healthy siblings. Am. J. Psychiat. 157, 416-421.

Stefanis, N., Frangou, S., Yakeley, J., Sharma, T., O’Connell, P., Morgan, K., Sigmudsson, T., Taylor, M., Murray, R., 1999.
Hippocampal volume reduction in schizophrenia: effects of genetic risk and pregnancy and birth complications. Biol. Psychiat. 46, 697-702.

Suddath, R.L., Casanova, M.F., Goldberg, T.E., Daniel, D.G., Kelsoe, J.R., Weinberger, D.R., 1989. Temporal lobe pathology in schizophrenia: a quantitative magnetic resonance imaging study. Am. J. Psychiat. 146, 464-472.

Suddath, R.L., Christison, G.W., Torrey, B.F., Casanova, M.F., Weinberger, D.R., 1990. Anatomical abnormalities in the brain of monozygotic twins discordant for schizophrenia. N. Engl. J. Med. 322, 789-794.

Turetsky, B., Cowell, P.E., Gur, R.C., Grossman, R.I., Shtasel, D.L., Gur, R.E., 1995. Frontal and temporal lobe brain volumes in schizophrenia. Arch. Gen. Psychiatry 52, 1061-1070.

Waldo, M.C., Cawthra, E., Adler, L.E., Dubester, S., Staunton, M., Nagamoto, H., Baker, N., Madison, A., Simon, J., Scherzinger, A., Drebing, C., Gerhardt, G., Freedman, R., 1994. Auditory sensory gating, hippocampal volume, and catecholamine metabolism in schizophrenics and their siblings. Schizophr. Res. 12, 93-106. 